\title{
Trust somebody but choose carefully : an empirical analysis of social relationships on an exchange market
}

\author{
Sylvain Mignot ${ }^{1}$, Annick Vignes ${ }^{2}$
}

February 3, 2019

${ }^{1}$ LEM, UMR 9221 and FGES, Lille Catholic University, sylvain.mignot@univ-catholille.fr

${ }^{2}$ ENPC and CAMS-EHESS, UMR 8557, annick.vignes@enpc.fr

\begin{abstract}
This article analyses the influence of trust on the functioning of a market for perishable goods, where there exists no quality signal and quantities can be scarce. On this market, agents can choose between bidding or exchanging through bilateral transactions. It is well accepted in economy that trust plays an important role in transactions but its definition and measurement stay, as far as we know, very elusive. Starting from the empirical analysis of a market with a peculiar organization, the Boulogne-sur-mer fish market, where people have the choice between trading through auctions or bilateral exchanges, we propose a measurement of trust, based on the dynamics of agents' encounters. We then analyze the differences in the social network structures and estimate how they affects the market outcomes.

We bring into the light that, when the transaction links on the auction market reflects the economic constraints of the partners, the relationships on the bilateral market depends on something more. Clearly, the prices of the bilateral transactions are the consequences of economics and non economics determinants. At first glance, the stable co-existence of two market structures looks like a paradox. Our results help to understand the distinctive characteristics and functioning of each sub-market. This discussion contributes to the debate about the efficiency of market structures.
\end{abstract}

Keywords: market design, trust, social networks.

J.E.L. codes: L14, D85, D47. 


\section{Introduction}

A fundamental assumption in economics is that rational individuals act in their own self interest. One implication is that, when trading, buyers are supposed to seek for the lowest price and sellers for the highest one and social interactions are not considered. In line with that, the literature has accepted for a long time the idea that centralized markets, with common information and no friction, are more efficient. Nevertheless, some recent results weaken this idea of centralized market dominance. Moreno \& Wooders (2010) show that decentralized organization allows both high and low quality units trade. Moreover, when frictions are small, the surplus realized is greater than the competitive surplus. Moreno \& Wooders (2016) studies non stationary dynamic decentralized markets with adverse selection. They show that when the horizon is finite, the surplus in the equilibrium exceeds the competitive surplus. It is now largely accepted that social relationships affect the efficiency of a market structure (centralized or decentralized) (Babus et al. 2013, Opp \& Glode 2016, Glode \& Opp 2017).

This article pays a particular attention to the influence of social connections on the process of transactions, whether a market is centralized or decentralized. We carry out an empirical analysis of a particular fish market (the Boulogne s/mer fish market). This wholesale market is organized through two sub-markets, one centralized (auctions), the other decentralized (pairwise transactions) and traders decide each day which sub-market they will go on. We exploit this remarkable organization to analyze the influence of loyalty between traders on the market outcome and the impact of market structures on trading relationships. In what follows, we postulate that trust is an output of loyalty that emerges from repeated trading links. We then measure the intensity of trust between traders and its influence, comparing the effects on centralized and decentralized markets.

According to the economic literature, trust influences very different phenomena, such as the amount of social expenditure (Camussi et al. 2018) or the dynamics of growth (Roth 2009). In spite of this interest, (Butler et al. 2015, 2016a,b), the measurement and definition of trust do not seem fully settled (Fehr 2009, Algan \& Cahuc 2014).

A market economy requires trust to insure the repetition of exchanges (Perelman 1998, Williamson 1993). Trust mixed with trustworthy behaviors turn out to be crucial for reduc-

ing transaction costs (Meidinger et al. 1999, Williamson \& Masten 1999), uncertainty (Guiso et al. 2008) or risk (Mccabe et al. 2007). It is often associated with cooperation (Milgrom et al. 1990). Cooperating can be a dominant strategy if a credible threat exists, and this threat could be the disappearance of trust (which corresponds to a come back to the non cooperative game).

The emergence and identification of the exact role of trust in economic interactions stay elusive. Does trust come from good institutions or does it help to reinforce the existing institutions? It appears that influence of trust depends on the market organization that traders operate in. 
When the institutions are weak, at a local or more global level, trust largely contributes to ameliorate the efficiency (Elsner \& Schwardt 2014, James 2015). Aghion et al. (2010) bring into the light a strong correlation between governance, regulation and trust.

Despite the importance of trust, the exact definition has to be clarified. Behavioral research on trust has been largely developed through laboratory and field experiments and help to categorize trust and trustworthiness. Experimental economics literature defines trust and trustworthiness in terms of behavior in specific games. The most familiar example is the investment game (sometimes called the trust game) introduced by Berg et al. (1995). Different definitions of trust and trustworthiness have been proposed within this context. A first mover trusts a second one if the return is more than the minimum possible amount (Burks et al. 2003, Ben-Ner \& Putterman 2009) or if a greater amount than the amount sent is returned (Schotter \& Sopher 2006, Chaudhuri \& Gangadharan 2007). Cox (2004) states that a first mover trusts a second mover if he sends an amount that makes himself vulnerable to a loss of utility. Vulnerabilityresponsiveness is the most important driver for trustworthiness Cox et al. (2016) and provide behavioral definitions of trust, that allow trust to be present without generosity.

An important result of experimental economics is that, under rather weak conditions, prices and quantities in competitive markets converge to the competitive equilibrium. But when trust is added to the game, the results differ significantly. When given a binary-choice between a trust game and a risky decision offering the same expected payoffs, individual choices are less risky when the agent of uncertainty is not nature: this is one more evidence that elements beyond mere outcome-based preferences (psychological loss) may influence the utility function (Bohnet et al. 2008). Reciprocity (and thus trust) may be capable of driving a competitive experimental market permanently away from the competitive outcome. When given the possibility to have reciprocal interactions, buyers are willing to pay prices above the sellers' reservation prices - they trust that the sellers will reciprocate by giving a high quality in return (Fehr et al. 1998).

If it is easy to understand how trust can influence pairwise exchanges, the way it may affect a centralized market remains unclear. The literature is quite sparse on this subject. In a context where investors have knowledge about trustees before transactions occur and where trustees compete with each other for access to investors, natural selection can favor both trust and trustworthiness, even when individuals interact through an anonymous prices mechanism. (Manapat et al. (2012)).

In the present article, we postulate that bilateral trust between individuals comes from repeated social relationships. In the line of Hernández et al. (2018), we define the level of trust between two persons by the number of encounters (number of days two persons traded together), relative to the number of encounters the same persons have with other traders: the more two 
persons exchange together, the higher the level of trust. We then assume that these bilateral social relationships affect the way people exchange together. This assumption implies that we consider a market where multiple couples of traders interact, as a social network.

The idea that social networks influence the markets functioning is not new. On markets with a high level of uncertainty on the goods exchanged, linking is essential for trading (Kirman \& Vignes 1990, Kranton \& Minehart 2000, 2001). The place occupied by an agent in the network (in terms of centrality for example) greatly influences its surplus (Corominas-Bosch 2004, Vignes \& Etienne 2011, Fafchamps et al. 2013).

A reason to create social links can be to gain information, as there are two ways to access it on a market. Agents can either form interpersonal connections and support a cost of linking, or acquire information from external sources of expertise and support the cost of searching: their choice depends on the differences between these two costs (Goyal 2009, Galeotti \& Goyal 2010).

Following this train of though, we build a specific social network, based on trust relationships. We first associate a trust index to each couple of agents (a buyer and a seller). We then consider that two traders trust each other when their trust index is high (belonging to the top $10 \%$ of the trust index distribution). From these sub-set of trust index, we create a network of trust relations. This procedure is done for both sub-markets. We postulate that the influence of the trust network should be more important on the decentralized market, where search costs can be substantial, especially when there exists no quality signals, as on the fish market. On an auction market where information is full, there are no costs of searching and no clear possibility of linking or reciprocity between buyers and sellers (at least on the sellers side). Trust should be more difficult to build.

A main objective of this article is to measure the existence and influence of trust on a market. Our fundamental hypothesis is that trust between agents influence the price of their transactions and that this influence differs from one market organization to the other. How much trust influences the market outcomes? How much the consequences of trust differ from a market to the other? A first novelty here consists in the analysis of an original database, which allows to compare two different market organizations. We then measure trust from observed relationships instead of surveys. A first result is that trust strongly influences the negotiated market, where the information is not centralized and where there exists no signal of information concerning the quality of the goods. Unsurprisingly, we find that trust has a low influence on the auctions outcome. A second originality consists in comparing two "trust networks", one on the auction sub-market, the other on the bilateral sub-market. The bi-partite network analysis reveals that being central (having a lot of trust relations) for a seller insures higher profit when being central for a buyer (having a lot of preferred sellers) implies paying lower prices, this effect being stronger on the decentralized sub-market. A third important result is that a strong 
correlation exists between trust index and centrality on the auction sub-market, that doesn't exist on the bilateral one. This result can be easily explained: on auctions, where the influence of trust is lower, central traders exchange regularly between themselves (because they are more present or sells bigger quantities), while on the pairwise market there is no relation between the probability for two traders to trust each other and their centralities on the network. Big traders can be linked together but also traders of different importance and this reveals something else than a pure economic pairwise relation.

This article is organized as follows: Section 1 outlines the main characteristics of the market and describes the database. Section 2 presents some descriptive statistics. The measure of trust is disclosed in Section 3 and Section 4 concerns the network analysis. The conclusion follows.

\section{The main market features and the data}

We present here some particular features of the Boulogne s/mer fish market, through the analysis of a detailed database, consisting of 300000 daily transactions on the period 2006-2007.

The market: The Boulogne s/mer fish market is located in the North of France near Belgium. It is considered as the most important fish market in France and one of the most important in Europe, in terms of quantity. On this market, the catch becomes scarce: this is due to the rarefaction of fish and a policy of quotas decided by the Common Fisheries Policy of the European Union, to protect the resource.

Its structure changed over time and for a long period, this market operated as a decentralized one. In the beginning of the $90 \mathrm{~s}$, the market moved to an auction system, following the E.U. instructions. The objective was to insure a more efficient market mechanism -avoiding unsold merchandise and preserving the surplus sharing. This new organization was soon rejected by both buyers and sellers, all arguing that the new market design was not in their favor. After collective bargaining between the different partners (institutions and unions of producers), a double mechanism has been introduced the 1st of April 2006, where both auction and bilateral sub-markets coexist. Surprisingly, this double organization stabilized within a very short period and still continue to function.

This market is a daily one, open 6 days a week. Transactions begin early in the morning. Agents are heterogeneous on both sides of the market. They are or sellers or buyers. There is no possibility of arbitrage. Sellers are boats owners and their boats are of different capacities. Small boats do not go very far and intervene regularly on the market. Bigger boats, going away for longer periods are present less regularly and sell bigger quantities of fish. Buyers are restaurant owners, retail buyers and fish processors. Buyers form then an heterogeneous population, facing different budget and time constraints. They can freely buy on both sub-markets. Most 
of the restaurant owners or retail buyers are present regularly when fish processors come less often. Each day, sellers have the possibility to choose how to sell their fish (auctions or pairwise exchanges). Once the sub-market chosen, they cannot change their strategy until the next day for practical reasons (costs of bringing the merchandise from one part of the market to the other are very high). Mignot et al. (2012) show the existence of two behaviors: some agents purchase most of the time on the same sub-market, when others switch regularly. Loyal sellers, the ones who change rarely, are mainly present on the bilateral market.

The auction market opens at 4 a.m. and always operates at the same place. During the studied period, the auction was an ascending one on 7 charts at the same time. It is a non cooperative game and the prices reflect the intensity of competition. The prices of the transactions are known by everybody and then, constitute a public information signal. Each lot offered for sale is carefully described (type of fish and quantities, name of the boat).

On this sub-market sellers can't choose their buyers: the buyers are not supposed to interact with the auctioneer, apart from the prices formation mechanism. But, of course, they can decide not to bid when the catch of certain boats is being sold. The time constraint is high while all the transactions take place in a very short time. Important volumes of fish are traded and transactions occur at a fast rate.

On the bilateral market, the prices are not displayed and emerge from a bargaining process. Buyers, who are retailers are looking for specific species, that correspond to their expected demand. Here agents have different source of private information, depending on their past history, their ability to bargain and transact and the special links they can have with agents of the other type (buyers or sellers).

The data: 200 boats are registered in this market and designated as "sellers" in what follows. 100 buyers purchase regularly, most of them on both sub-markets. The database we use covers a year and a half (2006-2007) where both sub-markets coexist. For each transaction, the date, the species, the characteristics of the traded fish (size, presentation, quality), buyer's and seller's identities, the type of trade mechanism (auction or negotiated), the quantity exchanged and the transaction price are known. The analysis of the database tells a story of heterogeneity. First statistical results exhibit heterogeneous behaviors in terms of quality and quantities exchanged, on the both sides of the market. On the period studied, the two sub-markets (auctions and negotiated) are of equal importance ( $45 \%$ of volume for the auctions market, $55 \%$ for the bilateral one): the same agents transact on the two "sub-markets" and the same types of fish are sold through both mechanisms (80 different species of fish are traded). Between $37 \%$ and $54 \%$ of each of the four main fish species (in term of quantities) are sold on the auction market which 
suggests an equivalent distribution of the production between the two market mechanisms.

\section{Stylized facts}

\subsection{Prices distributions}

Let's compare now the distributions of transactions prices and the agents behavior on both submarkets. In a first step, we compute the weekly aggregate prices per sub-market, using a classic Paasche index, which allows to take into account the heterogeneity of the goods:

$$
\hat{P_{w}}=\sum_{i=1}^{i=N}\left(p_{i, w}\left(\frac{q_{i, w}}{\sum_{i=1}^{i=N}\left(q_{i, w}\right)}\right)\right)
$$

$p_{i, w}$ being the price per kilo of a transaction ${ }^{1}$ in week $w, q_{i, w}$ the quantity sold in this transaction, and $N$ the number of transactions made in week $w$.

\begin{tabular}{llr}
\hline Price & Auction & Pairwise \\
\hline \hline Average & 2.38 & 2.94 \\
Median & 2.31 & 2.71 \\
Skewness & 0.87 & 3.00 \\
Kurtosis & 1.71 & 16.74 \\
Std dev & 0.51 & 0.82 \\
\hline \hline Test & test value & Pr \\
\hline Folded F test & 2.62 & 0.00 \\
Satterthwaite test & -5.63 & $<0.0001$ \\
\hline
\end{tabular}

Table 1: Descriptive statistics describing the weekly aggregate prices distributions on the two sub-markets. Both standard-deviation and average prices have significant differences. Observe a leptokurtic distribution of pairwise prices.

The first observation we can make from Tab.1 is that the prices are higher on the negotiated market (average and median) and that the prices distributions behave differently on the two markets. The very high kurtosis value on the bilateral market suggests a leptokurtic distribution, with fat tails: the "rare events", i.e., very low or high prices (outliers), are quite frequent. The higher standard-deviation confirms a higher uncertainty on the bilateral market. Finally we observe that both distribution have a positive skewness, which is way higher for the pairwise

\footnotetext{
${ }^{1}$ In this article, unless stated otherwise, all the prices considered will be prices per kilo.
} 
distribution. A positive skewness is associated to asymmetry : the mass of the distribution is concentrated on the left, where the values are lower, with a fat tail on the right. The "rare events" correspond to high prices.

The auction distribution, even if not following a normal law, is less asymmetric than the pairwise one (skewness of 0.87 vs. 3.00 and kurtosis of 1.71 vs. 16.74 on the bilateral market) and then exhibits relatively few high values. Clearly, pairwise exchanges are more risky and this result is in line with the literature.

\subsection{Buyers' and sellers' pairing}

We start by checking pairing strategies of buyers and sellers on both submarkets, looking a the distributions of the number of buyers (respect. sellers) that each seller (respect. buyer) transact with on the whole period considered (Fig.1 respectively Fig.2). Note that sellers trade with a high number of buyers on the negotiated market, while no clear pattern appears on auctions. The number of partners is not a strategic variable and this is not a surprise when considering that sellers can't directly act on the auction market.

When looking at the buyers strategy, we observe a propensity to exchange with a higher number of sellers on the negotiated market than on the auction one. We guess here that the trade network is more dense on the negotiated market that on the auction one.
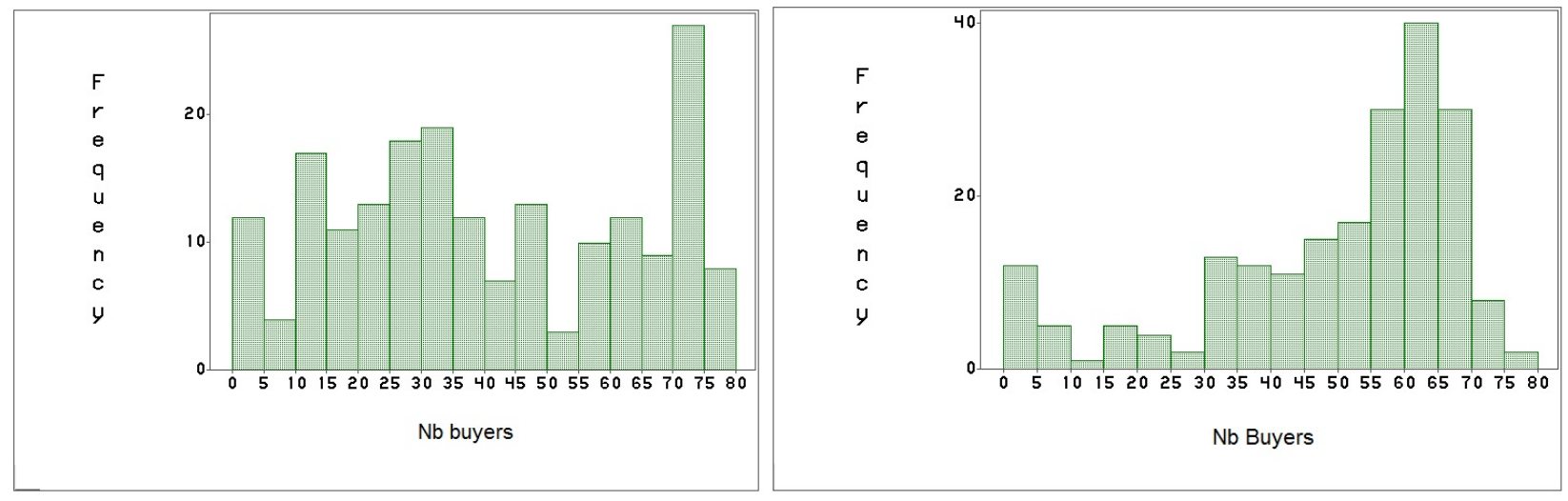

Figure 1: Number of buyers per seller on the auction (left) and negotiated (right) market. 

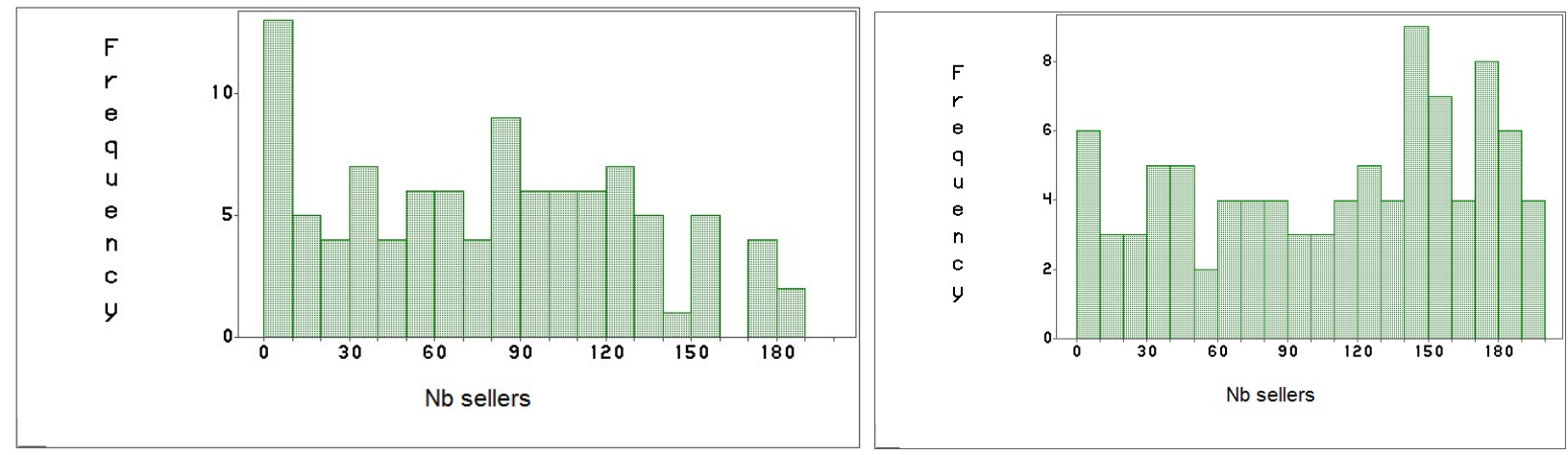

Figure 2: Number of sellers per buyer on the auction (left) and negotiated (right) market.

\subsection{Intensity of social links}

In a second step, we seek to estimate the intensity of social links for the different agents. Equation 2 represents, for an agent $i$, the ratio $\alpha_{i}$ of the number of transactions carried out by a trader divided by the number of agents he traded with on the whole period. This ratio should give a first estimation of the intensity of links for each agent. A high value should indicate an agent involved in loyal relationships.

$$
\alpha_{i}=\frac{\text { number of transactions }}{\text { number of traders }}
$$

The aggregate descriptive statistics are summarized in Tab.2.

\begin{tabular}{rcc}
\hline$\alpha_{i}$ buyers side & Auction & Negotiated \\
\hline \hline Mean & 13.51 & 19.63 \\
Median & 6.31 & 12.17 \\
\hline \hline$\alpha_{i}$ sellers side & Auction & Negotiated \\
\hline Mean & 16.77 & 23.15 \\
Median & 4.77 & 19.61 \\
\hline
\end{tabular}

Table 2: Mean and Median for buyers and sellers ratio distributions on both markets.

The mean and the median of $\alpha_{i}$ are higher on the bilateral market than on the auction one (for both buyers and sellers). For a given number of transactions, a buyer (respect. seller) trades with less sellers (respect. buyers) on the bilateral market than on the auction one. We observe a large difference between the mean and the median on the auction market and this can be due to a large number of people, coming rarely and buying at random. When looking at the data, we observe a high number of buyers coming rarely on auction market, while on the decentralized 
market, traders are present more regularly.

These first results suggest that the bilateral market is more risky, and that on this sub-market traders seem to choose their partners more carefully. Empirical evidence suggests the existence of loyal behavior on the decentralized market, which could help to mitigate the risk.

\section{A measure of trust}

Let's do now the hypothesis that auctions do not facilitate loyal strategies, while on the bilateral market people can choose with whom they exchange. Once on the decentralized market, people can either exchange with someone they trust or exchange at random. Because people are not present every day, it can happen that a very loyal agent has no other choice than exchanging with a non-usual suspect.

Consider now a bilateral market, where there is no arbitrage, composed by $\mathrm{N}$ buyers $i$, and M sellers $j$, who buy and sell regularly during $\tau$ periods, $\tau=1$...T. At each period $\tau$, a buyer (seller) can be present or not. When present, he can exchange with one or more sellers (buyers). In each matching, players trade with a partner they trust or with somebody else.

The diagram below sum up the different possibilities for each couple (seller, buyer) present at time $\tau$ on the market: 


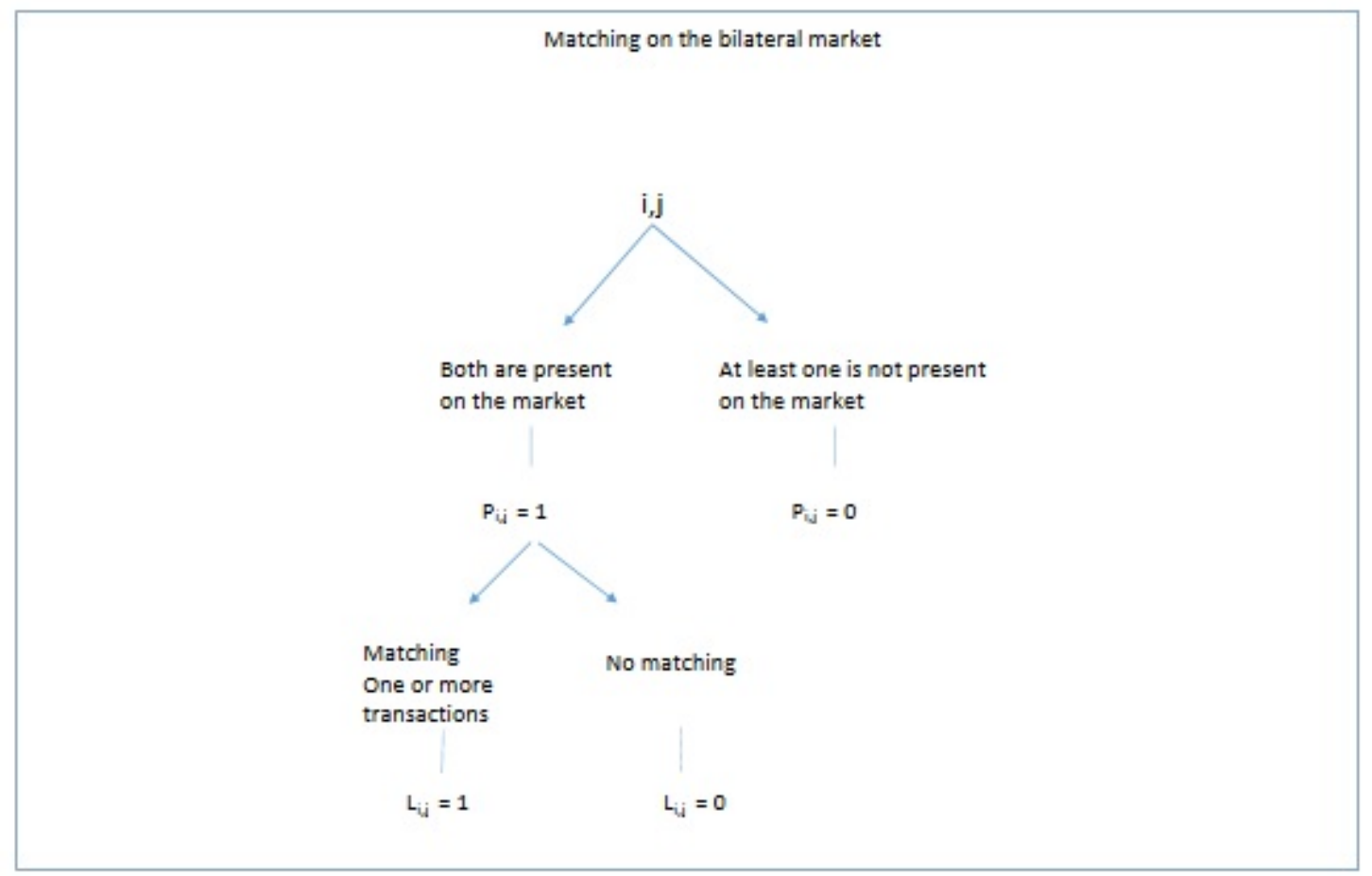

Figure 3: The different possibilities of matching (or not) for a couple (buyer/ seller).

\subsection{Looking for a signal of trust}

Let's now measure trust by the intensity of the matching. Do buyers and sellers match at random, following the opportunity of common presence or do they strategically choose their partners ? We first look at the correlation between $M_{i, j}$ the number of days a couple (buyer $i$ and seller $j$ ) is present on each sub-market, and $B_{i, j}$ the number of encounters. From Figure 3, we compute $M_{i, j}=\sum_{\tau=1}^{T} P_{i, j, \tau}$ and $B_{i, j}=\sum_{\tau=1}^{T} L_{i, j, \tau}$. Figure 4 and Figure 5 represent the relation between $M_{i, j}$ "being present at the same time" and $B_{i, j}$ "trading together" for each market. 


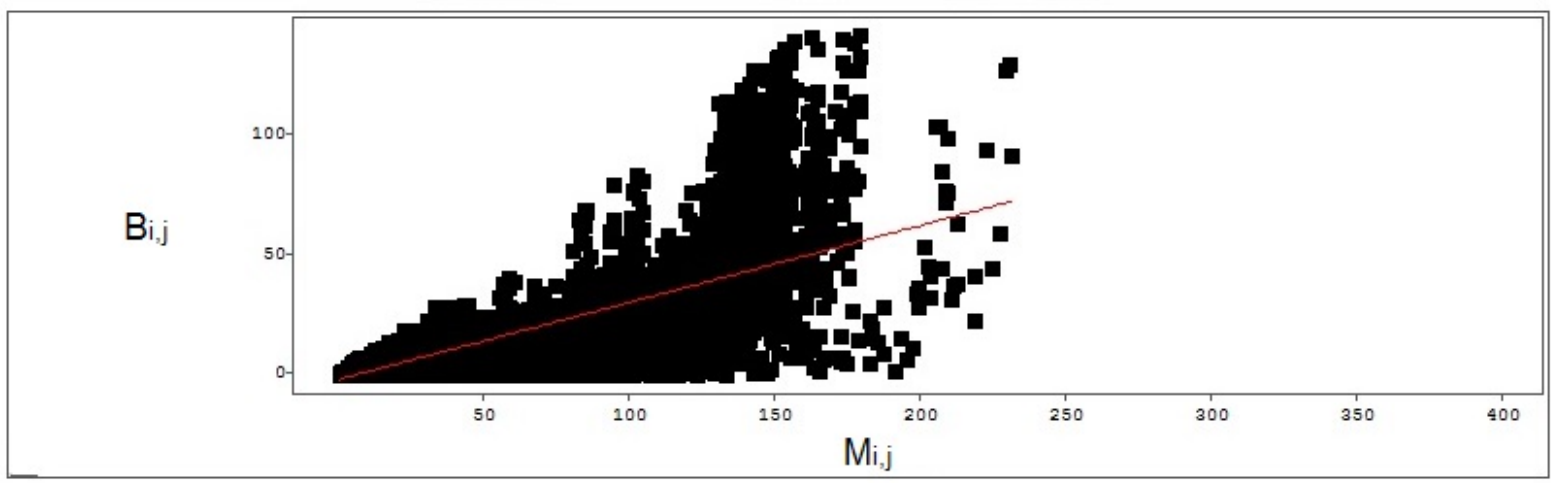

Figure 4: $B_{i, j}$ and $M_{i, j}$ on auction market.

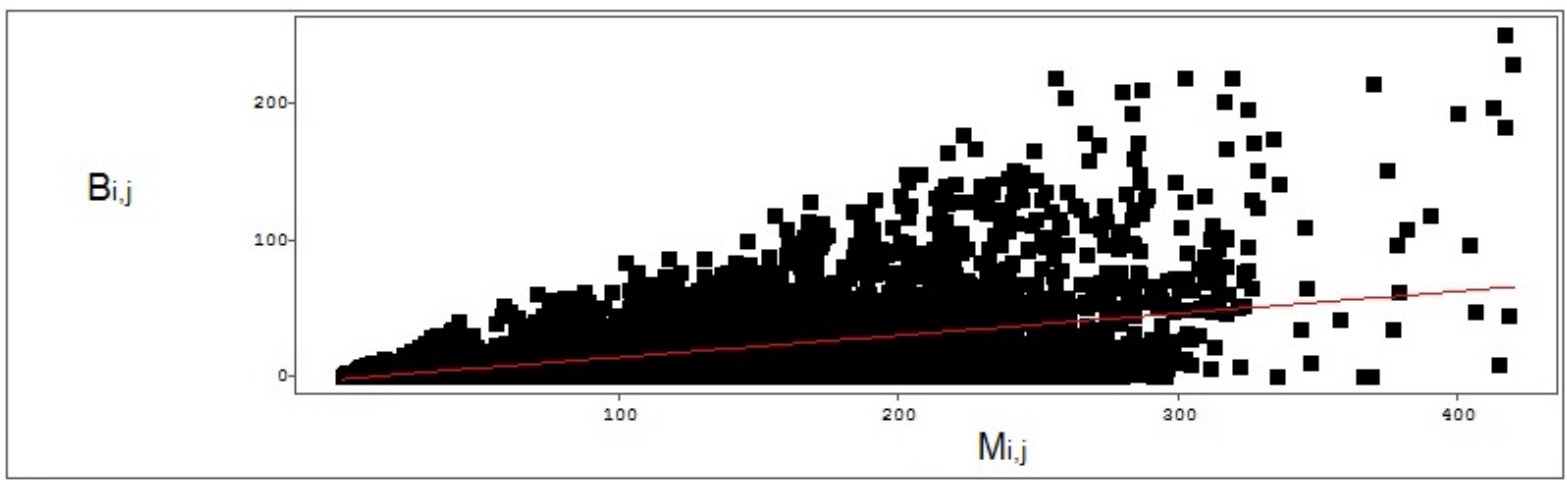

Figure 5: $B_{i, j}$ and $M_{i, j}$ on bilateral market.

Looking at the correlation between $B_{i, j}$ and $M_{i, j}$ (cf. Figure 4 and 5), we observe a stronger correlation between these two values when exchanges are centralized. The value is higher on the auction market than on the bilateral one (0.77 vs 0.58 ). Looking at the scatter-plot between these two variables (Figure 4 and Figure 5), we observe that two agents present at the same time on the auction market are more likely to exchange together than on the bilateral market. The linear regression of $B_{i, j}$ on $M_{i, j}$ (Table 3) shows that the $R^{2}$ of the linear fit is at 0.60 for the auction versus 0.35 for the decentralized market.

On the auction market, the only fact of being both present can explain most of the exchanges. When it comes to pairwise exchanges, the only fact of being present at the same time do not imply common trades. We conclude that pairwise trading depends on something more than random meeting. Our hypothesis is that exchanges on the bilateral market are conditioned to loyal relationships and trust behaviors. 


\begin{tabular}{|l|l|l|}
\hline & auction & negotiated \\
\hline$R^{2}$ & 0.60 & 0.35 \\
\hline Coef & 0.32 & 0.16 \\
\hline std dev & 0.002 & 0.002 \\
\hline Pr $>\mathrm{t}$ & $<0.0001$ & $<0.0001$ \\
\hline \hline Correlation & 0.77 & 0.58 \\
\hline
\end{tabular}

Table 3: Strength of the relation between $B_{i, j}$ and $M_{i, j}$ on the negotiated and the auction market.

Let's do now the assumption that the more people exchange together, the more they trust each other. It allows to define a trust index $R_{i, j}$ (Eq. 3) for each possible couple $i, j$ by a ratio of the total number of common encounters on the sum of the total encounters for $i$ and the total encounters for $j$.

$$
R_{i, j}=\frac{2 * B_{i, j}}{S_{i}+S_{j}}
$$

With $S_{i}=\sum_{j} B_{i, j}$ and $S_{j}=\sum_{i} B_{i, j}$

Calculating a trust index allows to measure the difference in agents' behaviors on both submarkets. We seek to verify if agents are more strategic on the negotiated market. Furthermore, looking at the distributions of trust index allows to pinpoint differences in trust level between the two market organizations.

The trust index will take values comprised between 0 and 1 . An index equal to 1 corresponds to the situation where two agents trade exclusively together. an index equal to 0.5 corresponds to a couple for which, for each partner, the mutual transactions represent half of their total number of transactions. a couple of agents who never trade together will have a null trust index. We then consider that the higher the value, the more they trust each other.

Figure 6 displays the distribution of trust index (equation 3) on the negotiated and on the auction market. For sake of clarity, the graph only displays the strictly positive values of $R_{i, j}$. 

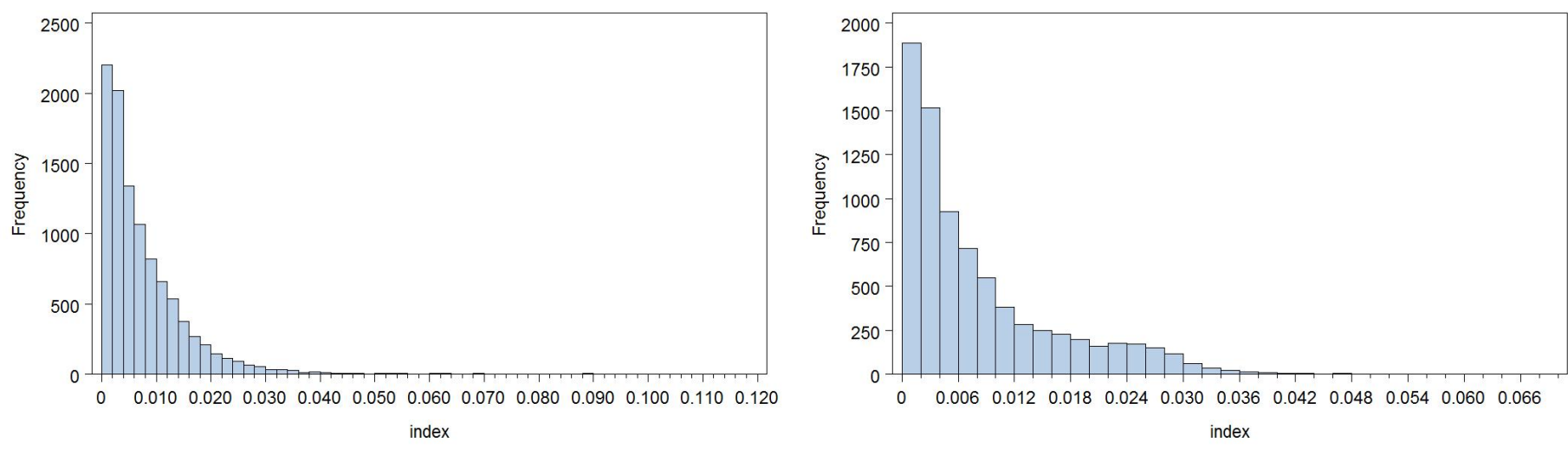

Figure 6: Distribution of trust index on the bilateral (left) and the auction (right) sub-markets (for active pairs)

To estimate the difference between the two distributions (auctions market and pairwise exchanges), we compute in Table (4) the observed value of $R_{i, j}$ of transacting couples for the two sub-markets. We also compute the values for all the possible pairs, including the ones that never transacted together, corresponding to null values. Observe that the main differences between the two $R_{i, j}$ distributions come from the shape of the distributions, with higher kurtosis and skewness on the pairwise market, which suggests highly heterogeneous linking behaviors on this sub-market. 


\begin{tabular}{|l|l|l||l|l|}
\hline & \multicolumn{2}{|c||}{$\begin{array}{c}\text { Distribution of positive values } \\
R_{i, j}>0\end{array}$} & \multicolumn{2}{c|}{$\begin{array}{r}\text { Total distribution } \\
R_{i, j} \geq 0\end{array}$} \\
\hline market & auction & negotiated & auction & negotiated \\
\hline Mean & 0.0082 & 0.0076 & 0.003 & 0.004 \\
\hline Median & 0.0049 & 0.0052 & 0 & 0.001 \\
\hline Q1 & 0.0021 & 0.0022 & 0 & 0 \\
\hline Q3 & 0.0115 & 0.0104 & 0.0034 & 0.0056 \\
\hline D9 & 0.0217 & 0.0168 & 0.0115 & 0.0123 \\
\hline Max & 0.069 & 0.12 & 0.069 & 0.12 \\
\hline Std Dev & 0.0082 & 0.0081 & 0.0066 & 0.007 \\
\hline Kurtosis & 1.99 & 23.34 & 7.60 & 28.95 \\
\hline Skewness & 1.49 & 3.45 & 2.66 & 3.89 \\
\hline \hline Number of pairs & 7843 & 10126 & 19500 & 19251 \\
\hline
\end{tabular}

Table 4: Trust index distributions on the bilateral and the auction market: for active pairs (strictly positive values) on the left side and all the possible pairs (total distribution) on the right side.

The two distributions are strongly different. The percentage of active pairs of traders (compare to the all possible pairs) is higher on the bilateral market (52\%) than on the auction market (40\%). The graph of exchanges is more dense on the bilateral market than on the centralized one.

A question now is to understand if the presence of trust and the differences in the trust distributions has an influence on the formation of prices on each market. A further step consists in exploring the influence of trust on the formation of prices, when transactions are pairwise and when the prices mechanism is an auction one.

\subsection{Influence of the trust index on prices}

Do personal links affect the trading outcome? The following GLM model (see equation 4), seeks to evaluate the influence of the trust index on the formation of transaction prices. Because of the heterogeneity of the variables, different dummies are included in the model ${ }^{2}$. The explained variable is the $\log$ of the price of each transaction. Dummies allow to take into account the weekday ("weekday" variable), the month ("month") and the year ("year") effects, as well as

\footnotetext{
${ }^{2}$ Regression of quantity on price per kilo being the regression of a choice variable on another choice variable, there exist risks of lack of identification or simultaneity bias. We choose not to include transactions quantities as explanatory variables in this paper. Including them doesn't change significantly any of our results.
} 
the species ("Specie" variable) effect. The results are given in Table 5.

$$
P_{i, j, \tau, t}=\beta_{1}+\beta_{2} \cdot R_{i, j}+\beta_{3} \cdot \text { Weekday }_{\tau}+\beta_{4} \cdot \text { year }_{k}+\beta_{5} \cdot \text { month }_{k}+\beta_{6} \cdot \text { Specie }_{k}+v_{i, j, \tau, t}
$$

\begin{tabular}{|l|l|l|l|l|l|l|}
\hline & \multicolumn{3}{|c|}{ Auction } & \multicolumn{3}{c|}{ Pairwise } \\
\hline Price & Coef & Std Dev & Pr $>\mathrm{t}$ & Coef & Std Dev & $\operatorname{Pr}>\mathrm{t}$ \\
\hline \hline Intercept & -0.07 & 0.12 & 0.56 & 0.73 & 0.08 & $<.0001$ \\
\hline$R_{i, j}$ & 0.62 & 0.13 & $<0.0001$ & 2.99 & 0.06 & $<.0001$ \\
\hline \hline R squared & 0.73 & 0.78 \\
\hline nb observations & \multicolumn{2}{|l|}{201047} & \multicolumn{3}{|c|}{279219} \\
\hline
\end{tabular}

Table 5: Log-level estimation results (Eq. 4) for both sub-markets.

Clearly, for a given weekday, month, year and specie, the trust index positively influences the price of transactions, and this influence is higher on the bilateral market than on the auctions. If the trust index between two persons would increase of 0.1 (the two persons reinforce their mutual trades), the price of their transactions would increase of nearly 30 percent through pairwise transactions. The increase through auctions should be lower even if significant. We obtain here two important results, which are that trust influences more the prices when transactions are bilateral and that this influence is positive. When a buyer trusts a seller, he/she agrees to pay a higher price.On a market with no quality signals and scarce resource, the risk (of getting no fish or getting fish of poor quality) is on the buyer side. Agreeing to pay a higher price to some particular sellers can be viewed as an insurance.

The fact that trust has a higher influence when the price results from bilateral negotiation, implies that the influence of trust on the negotiated market can't be fully explained by a simple reputation effect, as same traders exchange on both sub markets.

Considering this result, we suppose now that the structure of the exchanges network must exhibit significant differences on both sub-markets, differences we highlight in the following section.

\section{Network analysis}

Let's analyze now the bipartite networks designed by the trust indexes on both markets. We first analyze the structure of the two networks (centralized and decentralized), looking at the 
difference in density and clustering. In a second part, we evaluate the influence of centrality on the formation of prices. We finally estimate the nature of linking on the two sub-markets, between real trust and specialization.

\subsection{Bipartite trust network}

People are of different type (buyers or sellers) and a link exists when two agents of different types trust each other. We build for each sub-market a bipartite network formed of two types of nodes, buyers and sellers, on the total period. Two nodes of the same type cannot be linked.

Our definition of a link is based on the trust index (equation 3) as defined in Section 3. We then consider the entire distribution of trust index, including the null value (associated to couples with no trades). We have already explained that there is a possibility of random matching on this market. We assume now that trust indexes belonging to the $D 9$ ninth decile of the total distribution of trust (as displayed in Table 4) have a higher probability to result from strategical behaviors. In other words, we analyze the graph of the $10 \%$ strongest bilateral relations on each sub-market.

$$
\operatorname{Link}_{i, j}= \begin{cases}1 & \text { if } R_{j, i} \geq D 9 \\ 0 & \text { else }\end{cases}
$$

The resulting networks are displayed in figure 7. Although these graphs are highly dependent on the layout algorithm, we can guess that their structures differ, with the auction market looking more centralized. 

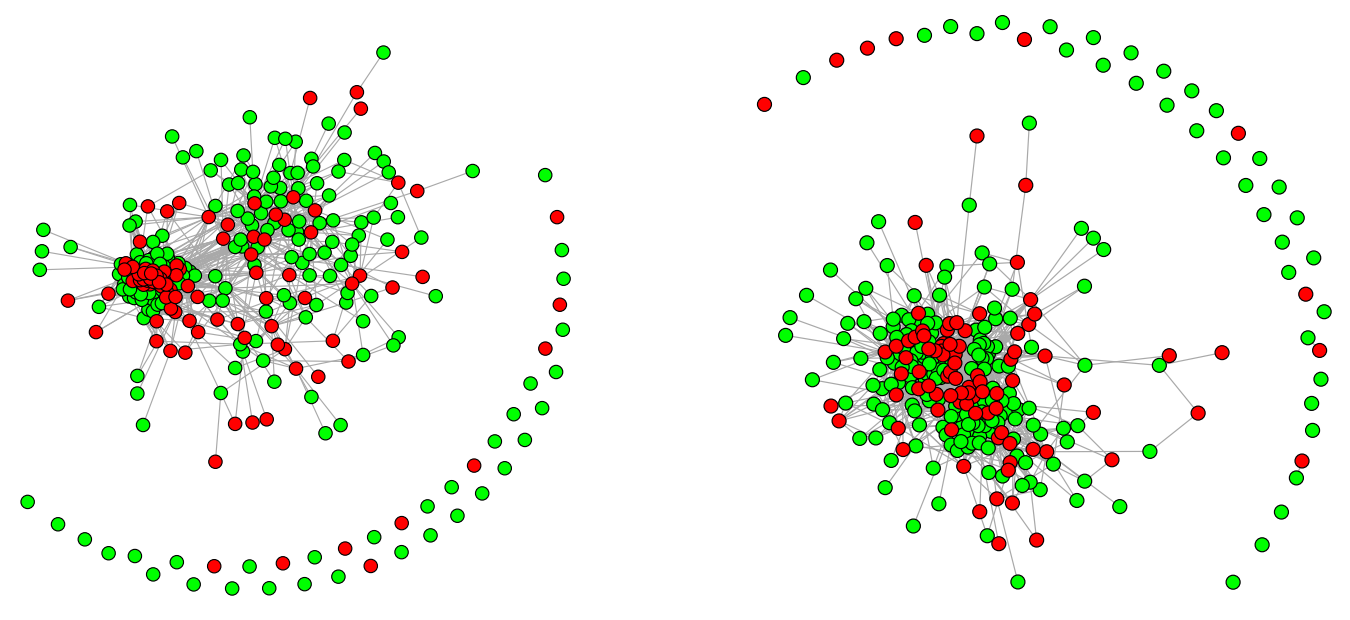

Figure 7: A bipartite graph for negotiated (left) and auction (right) sub-markets: sellers are in red, buyers in green.

The descriptive statistics (see Table 6) display more information.

\begin{tabular}{|l|l|l|}
\hline & Auction & Bilateral \\
\hline Nodes & 295 & 300 \\
\hline buyers & 100 & 93 \\
\hline sellers & 195 & 207 \\
\hline Links & 1950 & 1925 \\
\hline Density & 0.1 & 0.1 \\
\hline Clustering(reinforcement) & 0.71 & 0.39 \\
\hline
\end{tabular}

Table 6: Networks statistics.

The density of a network corresponds to the ratio between the number of existing links and the number of total possible links. The density value is between 0 and 1 . A density close to 1 reflects a dense network with an important number of links while a density close to 0 corresponds to sparse links. Both sub-markets have a similar density equal to 0.1 because of the choice of the thresholds.

The clustering coefficient we use here, as defined in Robins \& Alexander (2004) is an indicator 
of inter-sellers and inter-buyers closeness. It measures the reinforcement between two individuals rather than the clustering of a group of individuals.

In other words, consider that two sellers $S_{i}$ and $S_{j}$ trust the same buyer $B_{k}$. The probability for $S_{j}$ to trust a buyer $B_{l}, l \neq k$, is higher if $S_{i}$ trusts $B_{l}$. We observe from Table 6 that this coefficient is higher on the auction market (71\%) compared to the bilateral market (39\%). This suggests a higher specialization on the auction market (specific groups of buyers trust or regularly exchange with specific groups of sellers). This could be due to the diversity of the fish sold. Some sellers are specialized in particular varieties of fish and we can imagine that groups of buyers, with similar characteristics (restaurant owners or wholesalers) share the same preferences or the same constraints.

When it comes to the bilateral market this phenomenon is really weaker (the clustering coefficient is much lower), each buyer trusts a specific group of sellers. Loyalty links seem based on something else than economic specialization.

\subsection{The advantage of being central}

We now attribute to each agent, a vector or trust indexes and a coefficient of centrality in the trust network. The centrality we use in this article is defined by the number of trust ties that a node has, divided by the maximum number of ties he could have.

The former results suggest that the two sub-markets correspond to different types of individual behaviors, with more economic specialization on the auction market and a higher influence of social relationships when transactions are pairwise. The networks structures are different and it is now important to evaluate the consequences of these differences on the individual strategies. It is commonly accepted that, in social networks, actors who have more ties (i.e. are more linked to other actors) benefit from a favorable position. They may have alternative ways to satisfy their needs, and hence are less dependent on particular relationships. Similarly, a trader who has invested in creating only few links may have little bargaining power in that relationship, since he has no alternative partners with which to profitably trade. It is advantageous to be connected to those who have few options (the advantage of monopoly position); being connected to buyers (or sellers) who have many potential trading partners reduces one's bargaining power over the trade surplus.

To evaluate the influence of traders trust network on the market outcome, we analyze the effects of buyers' and sellers' centrality on prices. We use normalized degree centrality and measure its influence for both buyers and sellers $\left(\operatorname{deg}_{i}\right.$ and $\left.\operatorname{deg}_{j}\right)$.

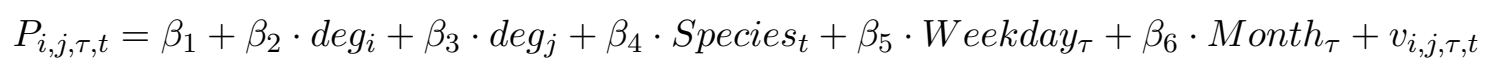


As already done in Eq. 4, we control for the influence of the day of the week $($ Weekday $)$ ), and the month $\left(\right.$ mont $\left._{\tau}\right)$. We also control for the global significance of the 80 species $\left(\right.$ Species $\left._{t}\right)$ exchanged. The explained variable is the $\log$ of the price per kilo of a transaction $t$. Each transaction $t$ involves a buyer $i$, a seller $j$ and a specie on a given day $\tau$.

\begin{tabular}{|l|l|l|l|l|l|l|}
\cline { 2 - 7 } \multicolumn{1}{c|}{} & \multicolumn{3}{c|}{ Auction } & \multicolumn{3}{c|}{ Pairwise } \\
\hline Parameter & coefficients & Std err & $\operatorname{Pr}>|t|$ & coefficient & Std err & $\operatorname{Pr}>|t|$ \\
\hline \hline Intercept & 0.03 & 0.12 & 0.76 & 0.87 & 0.08 & $<0.0001$ \\
\hline centrality buyer & -0.41 & 0.01 & $<0.0001$ & -0.59 & 0.01 & $<0.0001$ \\
\hline centrality seller & 0.49 & 0.03 & $<0.0001$ & 0.78 & 0.02 & $<0.0001$ \\
\hline \hline R squared & 0.74 & 0.79 & & \\
\hline
\end{tabular}

Table 7: Influence of centrality on prices for both sub-markets (log level estimation, Eq. 6).

The results are indicated in Table 7 . The usual causalities (dummies variables as year, month or day...) are not displayed. We observe that the position of an agent has a significant influence on the transactions prices on both sub-markets, and that this influence is higher on the bilateral market (higher R squared and higher coefficients). This influence is positive for sellers and negative for buyers and this is in line with previous results on markets. On a market with frictions (search costs, private information), it is advantageous for a seller to establish links with a large number of potential buyers. On the auction market, the information is centralized and there is no search costs. Prices result from the competition between buyers. Partnerships cannot help.

On the buyers side, the coefficient is higher (in absolute value) on the pairwise market. More central buyers pay cheaper prices and this reflects a higher bargaining power (due to the higher number of potential sellers).

From these results, we can deduce two things. First that traders have an interest to establish as many trust links as they can. Second, it is clear that each trader has interest to build strong relationships with lonely traders. It seems that there is a competition among traders that trust a same partner.

\subsection{Trust and centrality}

We now want to introduce the $R_{i, j}$ term in the regression in order to control for the bilateral trust effect and isolate the influence of the position in the trust network. But an important question 
remains : what is the intensity of the correlation between traders trust indexes and their centralities? Do these two variables represent two different phenomenas ? To answer this question we measure the correlation between the trust index and traders centrality on each market (Tab.8).

\begin{tabular}{|l|l|l|}
\cline { 2 - 3 } \multicolumn{1}{c|}{} & Auction & Pairwise \\
\hline Correlation for sellers & 0.62 & 0.26 \\
\hline Correlation for buyers & 0.39 & -0.19 \\
\hline
\end{tabular}

Table 8: Correlation between traders trust indexes and centralities.

Concerning the auction market, we observe a high correlation between the bilateral trust index of traders, and their respective centralities. Without surprise, we can conclude that interlinks on auctions result from the competition mechanism, more than from trust strategies. This is in line with the results in Section 4.1, Table 6, that exhibits a high clustering on the centralized market.

Meanwhile, the correlations are weak on the pairwise market. Agents with high trust indexes are not always central agents. Being central or trusting partners correspond to two different strategies.

While the correlation is high between trust and centrality on the auction market, it seems that two different effects correspond to these two different variables on the pairwise market. In what follows, we measure (cf. Eq. 7) the respective effects of centrality and trust on the decentralized market.

$$
P_{i, j, \tau, t}=\beta_{1}+\beta_{2} \cdot R_{i, j}+\beta_{3} \cdot \operatorname{deg}_{i}+\beta_{4} \cdot \operatorname{deg}_{j}+\beta_{5} \cdot \text { Species }_{t}+\beta_{6} \cdot \text { Weekday }_{\tau}+\beta_{7} \cdot \text { month }_{\tau}+v_{i, j, \tau, t}
$$

The results are displayed in Table 9 .

\begin{tabular}{|l|l|l|l|}
\cline { 2 - 4 } \multicolumn{1}{c|}{} & \multicolumn{3}{c|}{ Pairwise } \\
\hline Parameter & coefficients & Std err & $\operatorname{Pr}>|t|$ \\
\hline \hline Intercept & 0.82 & 0.08 & $<0.0001$ \\
\hline centrality buyer & -0.56 & 0.01 & $<0.0001$ \\
\hline centrality seller & 0.67 & 0.02 & $<0.0001$ \\
\hline$R_{i, j}$ & 1.34 & 0.07 & $<0.0001$ \\
\hline \hline R squared & 0.79 & \multicolumn{2}{l}{} \\
\hline
\end{tabular}

Table 9: Influence of trust and centrality on prices (log level estimation, Eq. 7).

As expected, introducing the trust index and centralities in the same regression decreases the influence of centralities on prices, and the influence of trust itself. But note that all coefficients 
stay significant. Even when adding the trust index in the regression, influence of centrality is far from being negligible. On the sellers side, it is clear that agents should better be central, with a high index of trust links. The effects of these two variables are positive and strongly significant. When coming to the buyers' side, the strategy of centrality seems to be more rational as it lowers the prices. But remember that bilateral trust increases prices, a buyer have to be cautious not being too dependent on some specific sellers. A buyer optimal strategy should result from a trade-off between being central to pay lower prices and investing in trust links to insure a stable level of quality of the good.

\section{Conclusion}

This article seeks to understand the influence of personal relationships on the outcome of a centralized market and a decentralized one. To this end, it drives an empirical analysis on a particular bi-market, the Boulogne s/mer fish market. On this market, the resource is scarce (due to the European quotas policy) and there exists no quality signal for a good which is highly perishable.

We first propose an empirical measure of trust based on the intensity of relationships between people. The more people exchanges together, the higher their trust index. A value of this index is associated to each possible pair (a buyer, a seller) of the market. For pairs which have never exchanged, the value of the index is zero.

We first establish that trust positively and strongly influences prices on both markets with a stronger causality when exchanges are pairwise. This stronger influence confirms that personal relations are more important on a pairwise market. Creating links is more costly on a bilateral market while it involves mutual agreement. On an auction market it is easy to buy or sell goods to strangers, when the transaction process is driven by a neutral auctioneer. This overprice associated to trust index can then be interpreted as an insurance cost, on a market with frictions costs, no quality signal and where the scarcity of the resource imply a risk for retailers. The fact that this influence is more important on the pairwise market compared to the auction one removes the possibility to explain completely this phenomenon by a reputation effect, traders being the same on both sub-markets.

Second, we analyze the structure of two "trust bipartite networks", one for each sub-market, for the pairs of agents with a trust index belonging to the higher $10 \%$ of the trust index distribution. If the density are the same (because of the very definition of these networks), the clustering values differs. A high value on the auction market suggests that exchanges are driven by specialization strategies. A low value on the pairwise market suggests that exchanges can be driven by something else than economic similarities.

We third measure the influence of centrality in these same networks. The position of an agent 
has a significant influence on the transactions prices on both sub-markets, and this influence is higher on the bilateral market. This influence is positive for sellers and negative for buyers and this is in line with previous results on markets. On a market with frictions (search costs, private information), it is advantageous for traders to link with a large number of other traders. On the auction market which pretty functions like a competitive one, prices result from the competition between buyers. Partnerships cannot help.

We finally associate a vector of trust values and a coefficient of centrality to each node (buyer or seller) of the network. An important question is to understand if these two values (trust and centrality) are correlated. An original result is that the level of correlation differs among the two markets. On the centralized auction market, trust corresponds to centrality. This is related to the particular functioning of this market which offers few possibilities for linking. While the offer side is represented by an auctioneer, sellers have no influence on the process of exchanges. Being central for a seller mean having a lot of buyers and this competition causes the prices to rise.

This result is not true anymore on the decentralized market. Trust index is not related to centrality but contribute to centrality to insure higher average prices to sellers involved in numerous trust relationships. Finally, a regressive estimation measures the respective influence of trust and centrality on the pairwise market outcome. If an optimal strategy for a seller is to be both central and with a high index of trust, a buyer will have to resolve a trade-off between being central (which lower the price) and being faithful, which increases the prices. Again, we believe that on a market with friction, no information signals and scarce resource, linking can help to minimize the risk. Being central shall help buyers to minimize the overprice of trust strategy.

For a fish retailer, being central is clearly an advantage, allowing to obtain goods at a lower price. Having strong trust bounds with specific sellers can serve as an insurance against the risk of lacking supplies of a satisfying level of quality. An optimal strategy to ensure both supply and reasonable prices would be to create trust links with non central sellers to avoid competition. On the Boulogne s/mer fish market, it is a good strategy to trust some partners but important to choose them carefully.

The stable co-existence of these two sub-markets where the same types of goods are traded by the same agents can seem paradoxical. Our analysis of the trust relationships help to resolve this paradox. The auction mechanism is an efficient one when people have no time for linking. They then trust the competitive market mechanism to insure an efficient redistribution of resources. But when they have time for linking, or exchanges involve rare goods, trusting some few partners can be optimal and the pairwise market mechanism allows this. 


\section{References}

Aghion, P., Algan, Y., Cahuc, P. \& Shleifer, A. (2010), 'Regulation and distrust', The Quarterly Journal of Economics 125(3), 1015-1049.

Algan, Y. \& Cahuc, P. (2014), Trust, growth, and well-being: New evidence and policy implications, in 'Handbook of economic growth', Vol. 2, Elsevier, pp. 49-120.

Babus, A., Kondor, P. et al. (2013), 'Trading and information diffusion in over-the-counter markets', Manuscript (RER Econometrica), London School of Economics .

Ben-Ner, A. \& Putterman, L. (2009), 'Trust, communication and contracts: An experiment', Journal of Economic Behavior $\&$ Organization 70(1-2), 106-121.

Berg, J., Dickhaut, J. \& McCabe, K. (1995), 'Trust, reciprocity, and social history', Games and economic behavior 10(1), 122-142.

Bohnet, I., Greig, F.and Herrmann, B. \& Zeckhauser, R. (2008), 'Betrayal aversion: Evidence from brazil, china, oman, switzerland, turkey, and the united states', American Economic Review 91, 294-310.

Burks, S. V., Carpenter, J. P. \& Verhoogen, E. (2003), 'Playing both roles in the trust game', Journal of Economic Behavior $\&$ Organization 51(2), 195-216.

URL: https://ideas.repec.org/a/eee/jeborg/v51y2003i2p195-216.html

Butler, J., Giuliano, P. \& Guiso, L. (2016a), 'Trust and cheating', The Economic Journal 126(595), 1703-1738.

Butler, J. V., Giuliano, P. \& Guiso, L. (2015), 'Trust, values, and false consensus', International Economic Review 56(3), 889-915.

Butler, J. V., Giuliano, P. \& Guiso, L. (2016b), 'The right amount of trust', Journal of the European Economic Association 14(5), 1155-1180.

Camussi, S., Mancini, A. L. \& Tommasino, P. (2018), 'Does trust influence social expenditures? evidence from local governments', Kyklos 71(1), 59-85.

Chaudhuri, A. \& Gangadharan, L. (2007), 'An experimental analysis of trust and trustworthiness', Southern Economic Journal pp. 959-985.

Corominas-Bosch, M. (2004), 'Bargaining in a network of buyers and sellers', Journal of Economic Theory 1, 35-77. 
Cox, J. C. (2004), 'How to identify trust and reciprocity', Games and economic behavior 46(2), 260-281.

Cox, J. C., Kerschbamer, R. \& Neururer, D. (2016), 'What is trustworthiness and what drives it?', Games and Economic Behavior 98, 197-218.

Elsner, W. \& Schwardt, H. (2014), 'Trust and arena size: expectations, institutions, and general trust, and critical population and group sizes', Journal of Institutional Economics 10(01), 107134.

Fafchamps, M., Ductor, L., Goyal, S. \& Leij, M. V. D. (2013), 'Social networks and research output', Review of Economics and Statistics .

Fehr, E. (2009), 'On the economics and biology of trust', Journal of the European Economic Association 7(2-3), 235-236.

Fehr, E., Kirchsteigerb, G. \& Riedlc, A. (1998), 'Gift exchange and reciprocity in competitive experimental markets', European Economic Review 42:1, 1-34.

Galeotti, A. \& Goyal, S. (2010), 'The law of the few', American Economic Review 100(4), 146892.

Glode, V. \& Opp, C. (2017), 'Over-the-counter vs. limit-order markets: The role of traders' expertise', Available at SSRN: https://ssrn.com/abstract=2697281.

Goyal, S. (2009), Connections: An Introduction to the Economics of Networks, Prince.

Guiso, L., Sapienza, P. \& Zingales, L. (2008), 'Trusting the stock market', The Journal of Finance LXIII(6), 2557-2599.

Hernández, L., Vignes, A. \& Saba, S. (2018), 'Trust or robustness? an ecological approach to the study of auction and bilateral markets', PloS one 13(5), e0196206.

James, H. S. (2015), 'Generalized morality, institutions and economic growth, and the intermediating role of generalized trust', Kyklos 68(2), 165-196.

Kirman, A. \& Vignes, A. (1990), Price Dispersion: Theoretical Coordination and Empirical Evidence from the Marseilles Fish Market, Macmillan.

Kranton, R. \& Minehart, D. (2000), 'Networks versus vertical integration', Rand Journal of Economics 31(3), 715-753.

Kranton, R. \& Minehart, D. (2001), 'A theory of buyer-seller networks', The American Economic Review Vol 91(3), 485- 508. 
Manapat, M. L., Nowak, M. A. \& Rand, D. G. (2012), 'Information, irrationality, and the evolution of trust', Journal of Economic Behavior $\& 3$ Organization .

Mccabe, K. A., Rigdon, M. L. \& Smith, V. L. (2007), 'Sustaining cooperation in trust games', Economic Journal .

Meidinger, C., Robin, S. \& Ruffieux, B. (1999), 'Confiance, réciprocité and cheap talk', Revue Economique 50, 5-44.

Mignot, S., Tedeschi, G. \& Vignes, A. (2012), 'An agent based model of switching: The case of boulogne s/mer fish market', Journal of Artificial Societies and Social Simulation 15 (2) 315 $(2), 3$.

Milgrom, P. R., North, D. C. \& R.Weingast, B. (1990), 'The role of institutions in the revival of trade: the law merchant, private judges, and the champagne fairs.', Economics and Politics 2(1).

Moreno, D. \& Wooders, J. (2010), 'Decentralized trade mitigates the lemons problem', International Economic Review 51(2), 383-399.

Moreno, D. \& Wooders, J. (2016), 'Dynamic markets for lemons: Performance, liquidity, and policy intervention', Theoretical Economics 11(2), 601-639.

Opp, C. \& Glode, V. (2016), (de) centralizing trade, in '2016 Meeting Papers', number 1591, Society for Economic Dynamics.

Perelman, M. (1998), 'The neglected economics of trust: The bentham paradox and its implications', American Journal of Economics and Sociology pp. 381-389.

Robins, G. \& Alexander, M. (2004), 'Small worlds among interlocking directors: Network structure and distance in bipartite graphs', Computational $\&$ Mathematical Organization Theory 10(1), 69-94.

URL: http://dx.doi.org/10.1023/B:CMOT.0000032580.12184.c0

Roth, F. (2009), 'Does too much trust hamper economic growth?', Kyklos 62(1), 103-128.

Schotter, A. \& Sopher, B. (2006), 'Trust and trustworthiness in games: An experimental study of intergenerational advice', Experimental Economics 9(2), 123-145.

URL: https://doi.org/10.1007/s10683-006-5386-y

Vignes, A. \& Etienne, J.-M. (2011), 'Price formation on the marseille fish market: Evidence from a network analysis', Journal of Economic Behavior $\&$ Organization 80. 
Williamson, O. (1993), 'Calculativeness, trust, and economic organization', The Journal of Law \& Economics 36(1), 453-486.

Williamson, O. \& Masten, S. E. (1999), 'The economics of transaction costs.', Northhampton, MA: Edward Elgar Publishing. . 